\title{
Three Europeans Join BULLETIN Editorial Board
}

Harry Leamy, chairperson of the MRS BULLETIN Editorial Board, has announced the appointment of three more scientists to the Board. The appointment of Minko Balkanski, University of Pierre and Marie Curie; Emanuele Rimini, University of Catania; and G.D W. Smith, Oxford University brings the Board to a total of 18 members and further extends the group's international scope, Leamy said.

See page 2 of this issue for a complete list of Editorial Board members.

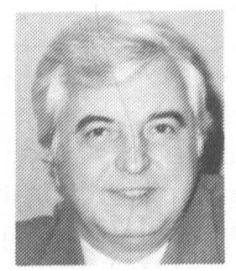

\section{MINKO BALKANSKI}

Minko Balkanski is director of the Solid State Physics Laboratory at the University Pierre and Marie Curie, Paris, France. His research interests are in the areas of solidstate spectroscopy. lattice dynamics, localized modes. band structures, electron-photon coupling, laser physics. optoelectronics, nonlinear optics. superionic conduction and intercalation in layered semiconductors.

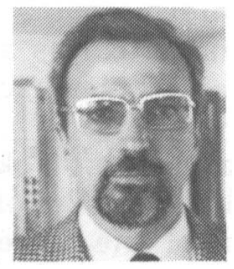

\section{EMANUELE RIMINI}

Emanuele Rimini is professor of structural matter, Department of Physics at the University of Catania, Catania, Italy. His research spans the areas of defects in metals and semiconductors, ion implantation. laser annealing, and channeling analysis of defects. He is a member of the Italian Physical Society as well as MRS. He has published over 150 technical papers and edited or authored a number of books and book chapters. Among his many professional activities, he has served on the advisory committee for MRS-Europe meetings and is chair of IBMM 86

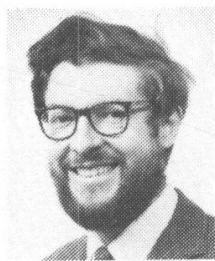

GEORGE SMITH

George Smith is a lecturer in metallurgy at Trinity College Oxford University. Oxford. England. Smith holds degrees in both metallurgy and chemistry, and his research work focuses on alloy elements in phase transformations in steels, heat treatment and long-term stability of nickelbase superalloys, behavior of catalyst surfaces, and oxidation of semiconductors. He is the author of nearly 100 technical papers and is currently involved in efforts to bring materials science and engineering teachings closer together.

\section{The BULLETIN is Your Forum}

The MRS BULLETIN is an important means of communication for materials scientists around the world. Do you have an opinion you would like to express, a topic you would like to discuss, or information on an important scientific event that you want your colleagues to know about? For details on how to get your message in to the BULLETIN, contact Gail Oare, Materials Research Society, 9800 McKnight Road, Suite 327, Pittsburgh, PA 15237; telephone (412) 367-3003.

\section{LETTERS}

To the Editor:

I have just finished reading the January/February 1985 edition of the MRS BULLETIN. I have one suggestion and one comment.

I appreciate the coverage of the Department of Energy SBIR Program and the publicity that these small businesses receive. Since I struck out on my own about a year ago, I have found that the problems of small businesses are certainly not the same as those of major corpurations. One consistent need is more recognition for the contributions that are made by these companies. The MRS article is a step in the right direction. It would be most useful to me, and probably of great interest to many MRS members, to have regular coverage of "small business issues." For example, the

SBIR Program must be renewed by

Congress in the near future. Its fate is not at all certain.

Russell F. Pinizzot to

President, Ultrastructure, Inc

Richardson, Texas
Send letters to the editor to: Editor

MRS BULLETIN 9800 McKnight Road Suite 327 Pittsburgh, PA 15237 